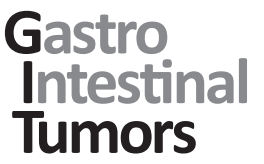

\title{
Rare Treatment for a Rare Tumor: Cryoablation of a Granular Cell Tumor
}

\author{
Lauren Derstine $^{a} \quad$ Erik Soule $^{b} \quad$ Naudare Shabandi ${ }^{b}$ Zarina Arutyunova ${ }^{c}$ \\ Chandana Lall $^{\mathrm{b}}$ Christopher Scuderi ${ }^{\mathrm{d}}$ Jerry Matteo $^{\mathrm{b}}$ \\ a University of Florida College of Medicine, Jacksonville, FL, USA; ${ }^{b}$ Department of Radiology, \\ University of Florida Health, Jacksonville, FL, USA; ' ${ }^{\mathrm{D}}$ epartment of Pathology, University \\ of Florida Health, Jacksonville, FL, USA; ${ }^{d}$ Department of Community Health and Family \\ Medicine, University of Florida Health, Jacksonville, FL, USA
}

\section{Keywords}

Cryoablation · Granular cell tumor · Neoantigen · Surgical alternative

\begin{abstract}
Background: Granular cell tumors (GCTs) or Abrikossoff's tumors are rare neoplasms known to originate from Schwann cells in the peripheral nervous system. These lesions are usually benign; malignancy only occurs in $1-2 \%$ of cases. Surgical resection is the traditional treatment method for GCTs, but it poses several risks and disadvantages related to the surgical incompatibility of the patient, the extended recovery time, and the chance of relapse. Cryoablation is becoming an increasingly favored method of treatment for tumors, both benign and malignant, due to its minimal invasiveness, natural analgesic properties, and ability to stimulate antitumor immunity. Cryoablation may contribute to the prevention of secondary and metastatic tumor growth in cases of malignancy by preserving tumor-associated antigen molecules for recognition by cell-mediated immunity. Methods: This article describes a novel method for GCT treatment using cryoablation. This technique exposes tumor tissue to extreme cold temperatures, effectively destroying tumor cells by irreversibly compromising their plasma membranes. To our knowledge, this is the first report in the literature of cryoablative techniques being used for GCT. Results: Cryoablation of this mass was successful with no complications. CT images during the procedure demonstrated circumferential coverage of the entire lesion with no injury to the surrounding tissues. Conclusion: Cryoablation can be used as an alternative to surgical intervention to treat malignant GCTs. This procedure is minimally invasive, less painful, and potentially effective in promoting antitumor immunity.
\end{abstract}




\section{Introduction}

Granular cell tumors (GCTs), also known as Abrikossoff's tumors, are rare neoplasms first discovered in 1926 by Abrikossoff and originally thought to arise from smooth-muscle tissue $[1,2]$. In the decades following, immunohistochemical and ultrastructural studies of the affected cells revealed that they are actually of neural-crest cell origin, derived from Schwann cells that are normally responsible for the production of myelin around neuronal axons in the peripheral nervous system [3]. GCTs are most commonly benign, with only 1-2\% of cases presenting as malignant, and usually occurring in middle-aged females [4]. GCTs can be found anywhere in the body, but commonly affected areas include the tongue, head, neck, and subcutaneous tissues. Granular cells in GCTs are histopathologically characterized by cytoplasmic granulation manifesting as microtubules, microvesicles, myelinic structures, and high-density regions [5]. The myelinic component of the granules, marked by the presence of sphyngomyelin and lipoproteins, is one indicator that GCTs originate from Schwann cells [4]. Granular cells have also tested positive for protein S-100, associated with neurodegeneration, and neuron-specific enolase, providing further support for GCTs' affiliation with Schwann cells [3].

GCTs can be diagnosed as malignant based on a number of characteristic features, including pleomorphism, heightened mitotic activity, distal metastasis, or rapid relapse following resection [3]. Traditional treatment for GCTs has consisted primarily of surgical resection, but more recent noninvasive and ablative techniques have shown varying degrees of success. The authors of a literature review on GCTs of the tracheobronchial tree suggested that surgical resection is the first choice of treatment for more symptomatic and larger tracheobronchial GCTs $(>8 \mathrm{~mm})$, but that noninvasive techniques such as neodymium/ yttrium-aluminum-garnet (Nd-Yag) laser therapy or electrocautery are effective for less severe cases [6]. Mohs micrographic surgery has also been employed as a simpler and more precise method of removing subcutaneous solitary nodules [7]. Ablative techniques have been used to treat GCTs in the form of endoscopic bipolar cautery, submucosal polidocanol injections, Nd-Yag laser, and the endoscopic injection of dehydrated alcohol [8-11].

This report demonstrates the utility of cryoablation for a 58-year-old woman with a past medical history of atypical ductal hyperplasia post-lumpectomy who presented to the emergency department with right-flank pain, dysuria, and microscopic hematuria. She was diagnosed with a urinary tract infection (UTI) and subsequently underwent a CT urogram with and without IV contrast. Cross-sectional imaging demonstrated an incidental soft tissue mass in the subcutaneous fat of her right flank continuous with the external oblique musculature. The mass was round with homogenous soft-tissue attenuation (mean: 52 Houndsfield units [HU]) measuring $1.8 \times 1.7 \times 1.7 \mathrm{~cm}$ (transverse $\times$ craniocaudal $\times$ anteroposterior). The mass enhanced (mean: $85 \mathrm{HU}$ ) on the nephrographic phase of enhancement (a 75-s delay postinjection) (Fig. 1a). No distortion of the contiguous muscle or stranding of the adjacent subcutaneous fat were noted.

Based on the incidentaloma observed on CT, the patient was scheduled for an imageguided biopsy (Fig. 1b). The tumor cells were large and contained intracytoplasmic eosinophilic granules, thought to represent lysosomes (Fig. 2a). The individual nuclei were small and regular with inconspicuous nucleoli. Large eosinophilic droplets could also be seen and were periodic acid Schiff (PAS)-positive (Fig. 2b). The tumor cells were diffusely positive (cytoplasmic and nuclear positivity) for S-100, highlighting their Schwannian origin (Fig. 2c). The biopsy did not demonstrate malignant features such as cellular atypia or abnormal mitotic figures. The lesion was therefore determined to be benign. Traditionally, recommended treatment for benign GCTs consists of curative surgical resection [12]. Cases of benign GCT typically do not metastasize and very rarely become malignant. However, GCTs have a recurrence rate of $20 \%$ when resections margins are not clear of tumor infiltration, 


\section{Gastro Intestinal Tumors}

Fig. 1. a Axial contrast-enhanced CT scan at the level of the kidneys, in a 58-year-old female who presented with flank pain, demonstrating an incidental round, enhanced soft-tissue mass in the subcutaneous tissue of the right flank measuring $1.8 \times 1.7 \times 1.7$ cm. b Axial unenhanced intraoperative CT image, with the patient prone, demonstrating biopsy of the soft-tissue mass with an 18-gauge BioPince full-core biopsy instrument (Argon Medical Devices).

\begin{tabular}{l|l}
\hline Gastrointest Tumors 2020;7:41-49 \\
\hline DOI: 10.1159/000504134 & $\begin{array}{l}\text { @ 2019 The Author(s). Published by S. Karger AG, Basel } \\
\text { www.karger.com/gat }\end{array}$ \\
\hline
\end{tabular}

Derstine et al.: Cryoablation of a Granular Cell Tumor
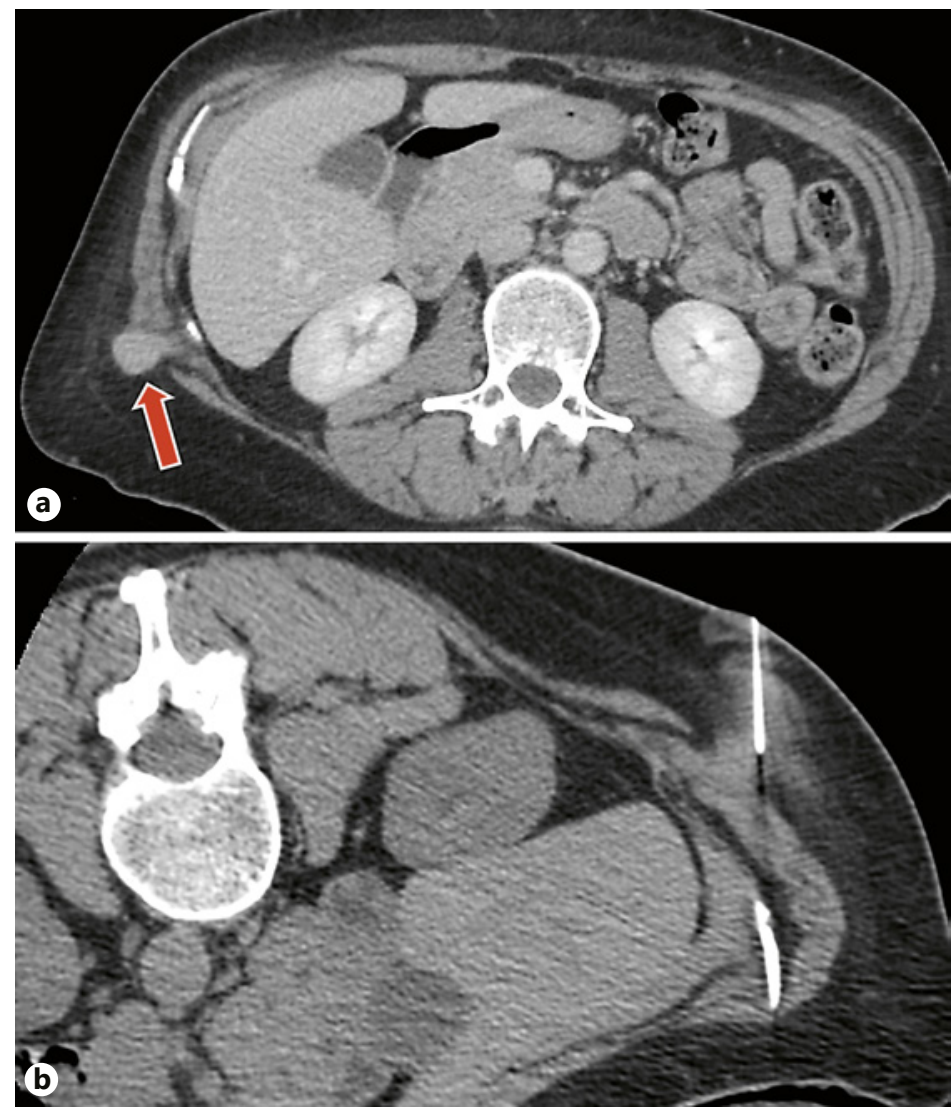

and of $2-8 \%$ even when these margins are completely clear [13]. Cryoablation may decrease recurrence by stimulating systemic antitumor immunity [14]. The patient desired minimally invasive treatment and opted for percutaneous cryoablation over surgery.

\section{Materials and Methods}

For the CT-guided biopsy, a 17-gauge coaxial introducer needle was positioned in the mass with the patient prone in the CT gantry. A total of 3 core biopsy specimens of the mass were obtained using an 18-gauge BioPince needle (Argon Medical Devices, Frisco, TX, USA) and submitted directly to the pathologist.

For CT-guided cryoablation, the patient was positioned prone on the CT gantry and prepped in the usual sterile fashion. Limited CT images were obtained to delineate the right-flank soft-tissue mass abutting the oblique musculature and for procedure planning. The skin was marked. Using CT guidance, 3 17-gauge 1.5 IceRod CX cryoablation needles (Galil Medical, Arden Hills, MN, USA) were inserted by direct CT fluoroscopy into the round, homogeneous, subcutaneous mass bracketing the tumor, two in the superomedial and superolateral portion of the tumor and the third within the inferior portion of the tumor. Warm saline in a sterile glove was placed on the skin over the cryoablation zone to help prevent frostbite.

\section{Results}

Limited CT images were obtained at 5- and 9-min intervals to evaluate the progression of the ice ball (Fig. 3a, b). This demonstrated circumferential coverage of the entire mass. Following removal of the cryoablation probes, limited CT was performed, revealing new 


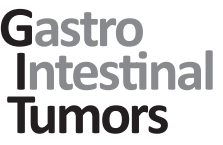

Fig. 2. GCT pathology microscopy of 58-year-old female who presented with flank pain. a Histopathology image demonstrating large tumor cells (black arrows) percolating between skeletal muscle fibers (blue arrows) HE. $\mathbf{b}$ Histopathology image demonstrating tumor cells with ill-defined cytoplasmic borders and abundant granular material (black arrows). Larger eosinophilic droplets are also present (yellow arrows). HE. $\times 40$. c Immunohistochemistry image is diffusely positive and highlights the lysosomes (granular material) in the tumor cells. S-100. $\times 10$.

\begin{tabular}{l|l}
\hline Gastrointest Tumors 2020;7:41-49 \\
\hline DOI: 10.1159/000504134 & $\begin{array}{l}\text { @ 2019 The Author(s). Published by S. Karger AG, Basel } \\
\text { www.karger.com/gat }\end{array}$ \\
\hline
\end{tabular}

Derstine et al.: Cryoablation of a Granular Cell Tumor
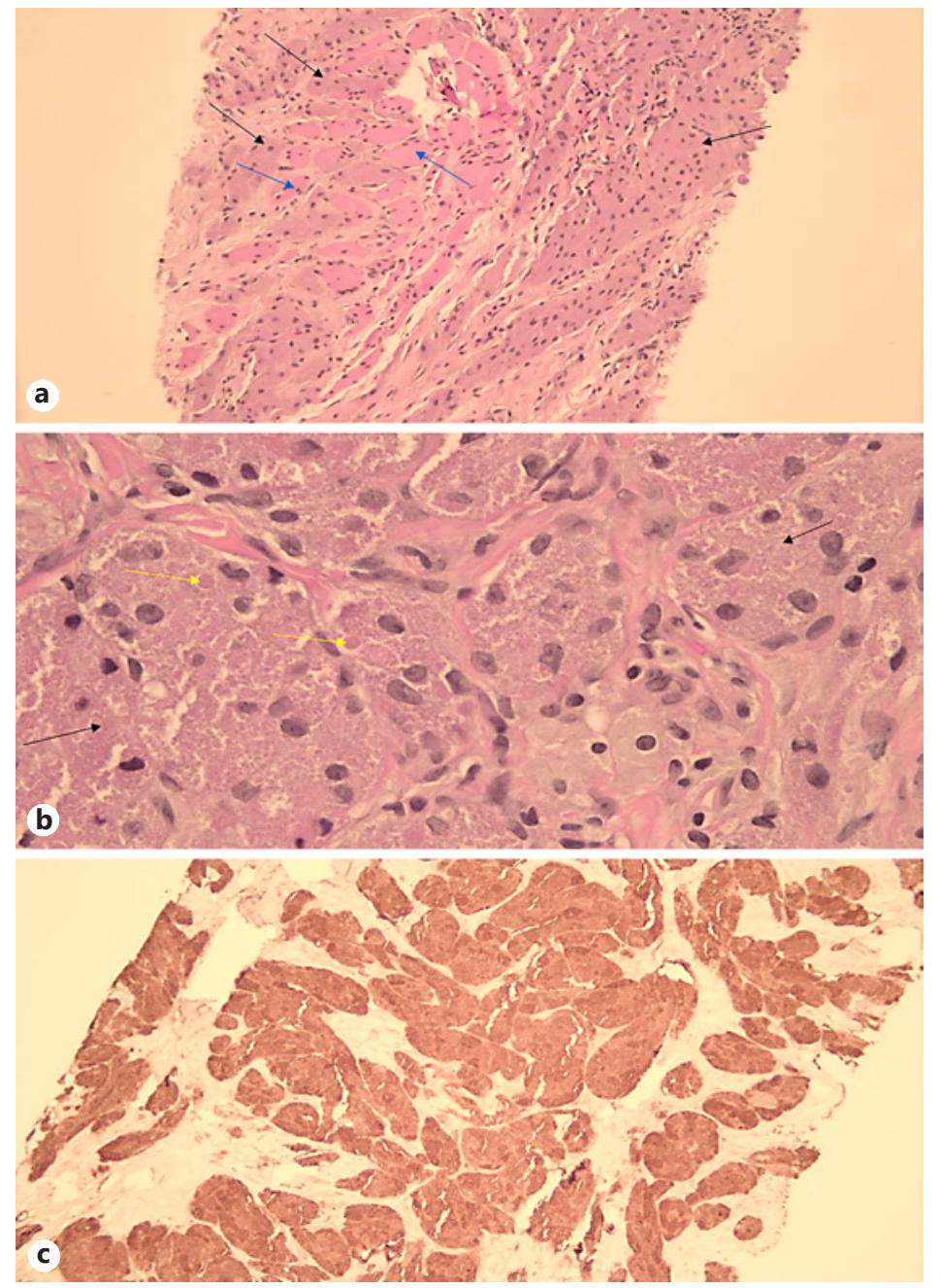

hypodensity interposed between the mass and oblique musculature consistent with the ice ball (Fig. 3c). No hemorrhage or injury to the surrounding structures was noted. At the 6-week follow-up, imaging revealed a significant reduction in lesion size and no internal enhancement, evidence that the tumor tissue had been rendered inviable by the cryoablation procedure (Fig. 4).

\section{Discussion}

While surgical resection has long been considered the primary method of treatment for GCTs, minimally invasive and ablative methods are increasingly being used as more practical alternatives. There are many unique advantages associated with cryoablation which are unattainable through surgical resection and other ablative techniques. For instance, cryoablation is a minimally invasive procedure, making it a safe and effective option for a wider range of patients. Recovery time is shorter and the procedure is less painful due to the intrinsic analgesic properties of ice [15]. It has also been shown that this technique poses a minimal threat to nontargeted periarticular tissue architecture within the treatment margins during percutaneous bone ablation [16]. Finally, cryoablation in conjunction with preablation embo- 


\section{Gastro Intestinal Tumors}

Fig. 3. Axial intraoperative CT image at the level of the kidneys, in a 58-year-old female who presented with flank pain, demonstrating two 17-gauge 1.5 IceRodCX cryoablation probes in the medial and lateral portion of the mass (a) and an additional 17-gauge probe in the inferior portion of the mass (b). The mass has "disappeared" as the cryoablation ice ball is closer in attenuation to the surrounding fat tissue than the index mass. c Immediate postprocedure axial CT shows increased conspicuity of the mass versus the intraprocedural images. There is faint hazy hyperdensity surrounding the mass and hypodensity at the interface of the mass and the adjacent musculature representing residual ice. This atypical appearance is related to surrounding fat density and is in contradistinction to the typical appearance of a cryoablation ice ball in solid organ tissue.

\begin{tabular}{l|l}
\hline Gastrointest Tumors 2020;7:41-49 \\
\hline DOI: 10.1159/000504134 & $\begin{array}{l}\text { @ 2019 The Author(s). Published by S. Karger AG, Basel } \\
\text { www.karger.com/gat }\end{array}$ \\
\hline
\end{tabular}

Derstine et al.: Cryoablation of a Granular Cell Tumor
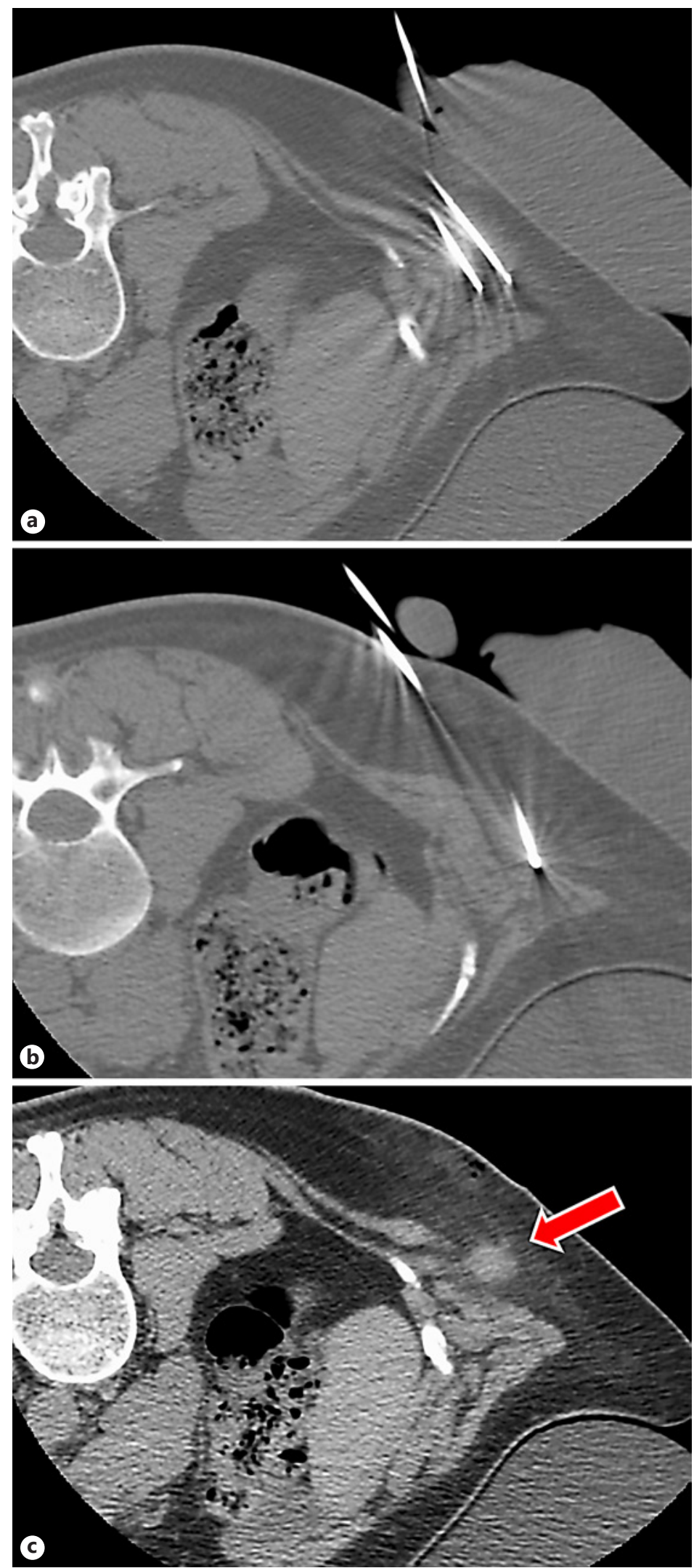
Gastro

Intestinal

Tumors

Fig. 4. A 6-week postoperative axial CT scan at the level of the kidneys, in a 58-year-old female who presented with flank pain, demonstrating a soft-tissue mass in the subcutaneous tissue of the right posterior flank (a), now measuring $1.7 \times 1.4 \mathrm{~cm}$ (previously measured $1.7 \times 1.9 \mathrm{~cm}$ ) after cryoablation (b). There are adjacent inflammatory changes of the surrounding subcutaneous fat and no internal gas. c There is no internal enhancement (37 HU on precontrast exam and $34 \mathrm{HU}$ on postcontrast exam). This is evidence of no viability.

\begin{tabular}{l|l}
\hline Gastrointest Tumors 2020;7:41-49 \\
\hline DOI: 10.1159/000504134 & $\begin{array}{l}\text { ○ 2019 The Author(s). Published by S. Karger AG, Basel } \\
\text { www.karger.com/gat }\end{array}$ \\
\hline
\end{tabular}

Derstine et al.: Cryoablation of a Granular Cell Tumor
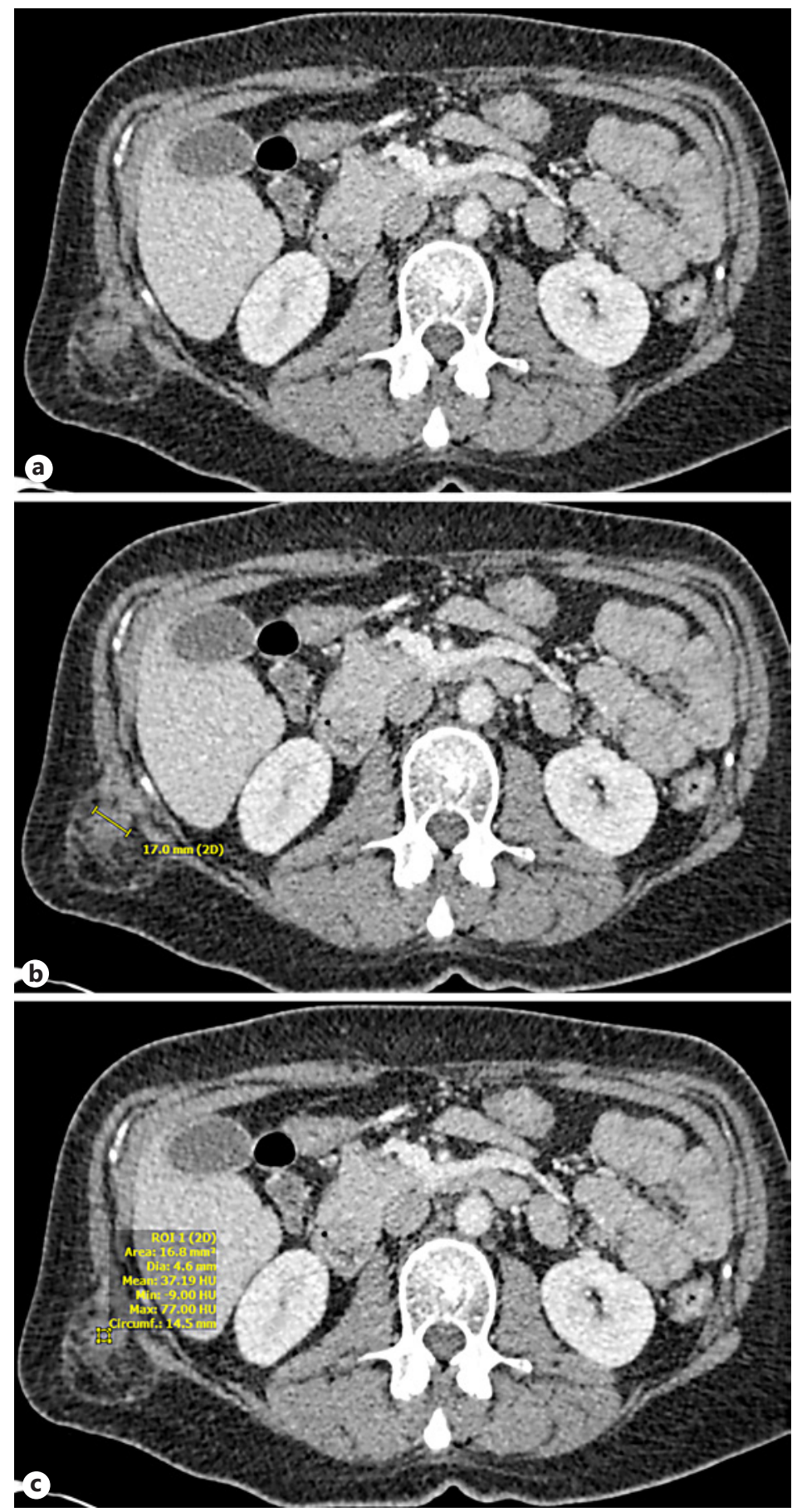
latory effects, cryoablation seems to offer a unique advantage by safeguarding the structural integrity of tumor-associated antigen (TAA) molecules while simultaneously subjecting tumor cell membranes to irreversible damage [18]. Cryoablation therefore results in a greater percentage of activated dendritic cells after treatment compared to RFA. RFA and microwave ablation have been shown to induce coagulative necrosis while preserving tumor cell membranes, leading to a greater chance of recurrence compared to cryoablation.

The antitumor immunity benefits of cryoablation stem from its ability to maximize the necrosis/apoptosis ratio while protecting TAA molecules, which would be destroyed by thermal techniques [19]. It is postulated that maximizing the necrosis/apoptosis ratio serves as a danger signal to the immune system, facilitating an immunologic elimination of the offending antigens and reducing anergy in tumor-specific T cell clonal lineages [20].

Recent studies have attempted to explain the mechanism behind the systemic antitumor immunity induced by cryoablation. An experimental study showed that, compared with excision, cryoablative techniques inhibit the growth rate of secondary and metastatic tumors; this was associated with elevated plasma cytokine (IL-1 $\alpha$ and TNF- $\alpha$ ) levels after cryoablation, which may contribute to stimulation of a systemic immune response [21]. The authors concluded that these results gave reason to attribute early tumor growth inhibition to nonspecific immune responses like the release of cytokines, rather than to a specific T cell-dependent response. However, another study, using $\mathrm{T}$ cell receptor repertoire analysis and immune profiling following cryoablation, demonstrated the expansion of a small subset of $\mathrm{T}$ cells in the tumor tissue as well as in the peripheral blood, again indicating a systemic immune response against distant secondary lesions induced by cryoablation [22].

There is increasing evidence that surgical resection of tumor tissue may actually promote relapse and secondary tumor growth, providing further reason to opt for minimally invasive techniques if possible $[23,24]$. For example, intraoperative tumor manipulation contributes to tumor cell dissemination or seeding by stimulating metastatic embolization and forcing tumor cells into the lymphatics where they can then enter circulation [25, 26]. Cell-platelet interactions which form cell aggregates may promote relapse as they are able to safeguard residual tumor cells during and after excision [27]. It has been shown that tumor excision can also alter the properties of neoplastic cells, increasing their tumorigenicity, thus enabling the activation of previously dormant tumor cells [25]. This is supported by observations of decreased apoptosis and heightened proliferation following primary tumor removal, as well as an increase in several blood-borne factors which potentiate tumor growth.

A study on the influence of surgical procedures on the metastasis of primary breast cancer showed that the surgical wound promoted tumor growth and the pulmonary metastasis of cancer cells [28]. Finally, the postoperative stress response induces immunosuppression immediately after surgery by quickly reducing the activity of natural killer cells and lymphocyte-activated killer cells, which usually play a significant role in immune antitumor surveillance [29]. Tumor cells are then able to bypass the host immune response, creating an immunologic window of opportunity for accelerated tumorigenesis.

In contrast, the potential immunomodulatory benefits of cryoablation are particularly useful in cases of metastasis as they may induce a systemic antitumor response which reaches all affected regions and hinders further secondary growth [15]. While malignancy and subsequent metastasis in GCTs is extremely rare, there are reported cases of metastasis in both malignant GCTs (particularly of the esophagus) and histologically benign GCTs [6, 7]. There are thus opportunities for the application of cryoablation and its possible immune benefits in treating GCTs specifically, especially those that are metastatic or malignant. Furthermore, cryoablation may be utilized in the future to treat tumors that cannot be reached percutaneously, given they are accessible and do not obstruct vital structures. 


\section{Conclusion}

Cryoablation is a viable option for treating GCTs due to its minimal invasiveness, analgesic properties, and antitumor immune stimulation. Follow-up imaging for our patient showed a reduction in the size of the lesion and no internal enhancement, i.e., there was no evidence of viability. As a favorable alternative to traditional surgical resection, cryoablation and interventional oncologic techniques show promise for the treatment of malignant and metastatic tumors.

\section{Statement of Ethics}

Informed consent was obtained from the patient prior to the study. The privacy and confidentiality of the patient's personal information was protected. Submission of research protocol to an Institutional Review Board is not required for a single case in our institution. Research was conducted ethically in accordance with the World Medical Association Declaration of Helsinki.

\section{Disclosure Statement}

The authors declare no conflicts of interest.

\section{Author Contributions}

Lauren Derstine wrote the Abstract, Introduction, Discussion, Conclusion, and references. Erik Soule was the senior editor. Naudare Shabandi wrote Materials and Methods, Results, and the figure legends for the CT images. Zarina Arutyunova provided pathology images and wrote the legends for the pathology images. Chandana Lall assisted with revision. Christopher Scuderi, the primary care physician, assisted with revision. Jerry Matteo, attending surgeon, designed study and assisted with writing the abstract and with the overall revision.

\section{References}

1 Abrikossoff AI. Über Myome, ausgehend von der quergestreiften willkürlichen Muskulatur. Virchows Arch Path Anat. 1926;260(1):215-33.

2 Montojo J, Echarri R, Santana A, Micó A, Gamboa J, Cobeta I. A multifocal granular-cell tumor of the upper airways. Acta Otorrinolaringol Esp. 1999 Aug-Sep;50(6):498-501. Spanish.

3 Garín L, Barona R, Basterra J, Armengot M, Alemany P, Martorell MA. Granular cell tumor (Abrikossoff's tumor). A review and our experience. An Otorrinolaringol Ibero Am. 1992;19(3):249-64. Spanish.

4 Lazar RH, Younis RT, Kluka EA, Joyner RE, Storgion S. Granular cell tumor of the larynx: report of two pediatric cases. Ear Nose Throat J. 1992 Sep;71(9):440-3.

5 Bitar M, Khalid AA, Mohammad IF. Granular cell tumor: case report. J Dermatol and Dermatol Surg. 2011; 15(1):25-7.

6 van der Maten J, Blaauwgeers JL, Sutedja TG, Kwa HB, Postmus PE, Wagenaar SS. Granular cell tumors of the tracheobronchial tree. J Thorac Cardiovasc Surg. 2003 Sep;126(3):740-3.

7 Gardner ES, Goldberg LH. Granular cell tumor treated with Mohs micrographic surgery: report of a case and review of the literature. Dermatol Surg. 2001 Aug;27(8):772-4.

8 Choi PM, Schneider L. Endoscopic Nd:YAG laser treatment of granular cell tumor of the esophagus. Gastrointest Endosc. 1990 Mar-Apr;36(2):144-6.

9 Cunningham L, Wendell G, Berkowitz L, Schulman ES, Promisloff R. Treatment of tracheobronchial granular cell myoblastomas with endoscopic bipolar cautery. Chest. 1989 Aug;96(2):427-9.

10 Maccarini MR, Michieletti G, Tampieri I, Triossi O, Bertinelli E, Casetti T. Simple endoscopic treatment of a granular-cell tumor of the esophagus. Endoscopy. 1996 Oct;28(8):730-1.

11 Moreira LS, Dani R. Treatment of granular cell tumor of the esophagus by endoscopic injection of dehydrated alcohol. Am J Gastroenterol. 1992 May;87(5):659-61.

12 Elkousy H, Harrelson J, Dodd L, Martinez S, Scully S. Granular cell tumors of the extremities. Clin Orthop Relat Res. 2000 Nov; 380:191-8. 
13 Fanburg-Smith JC, Meis-Kindblom JM, Fante R, Kindblom LG. Malignant granular cell tumor of soft tissue: diagnostic criteria and clinicopathologic correlation. Am J Surg Pathol. 1998 Jul;22(7):779-94.

14 Niu L, Chen J, He L, Liao M, Yuan Y, Zeng J, et al. Combination treatment with comprehensive cryoablation and immunotherapy in metastatic pancreatic cancer. Pancreas. 2013 Oct;42(7):1143-9.

15 Soule E, Bagherpour A, Matteo J. Freezing Fort Knox: Mesenteric Carcinoid Cryoablation. Gastrointest Tumors. 2017 Sep;4(1-2):53-60.

16 Vikingstad EM, de Ridder GG, Glisson RR, Cardona DM, DiPalma D, Eward WC, et al. Comparison of acute histologic and biomechanical effects of radiofrequency ablation and cryoablation on periarticular structures in a swine model. J Vasc Interv Radiol. 2015 Aug;26(8):1221-1228.e1.

17 Harmon TS, Matteo J, Meyer TE, Kee-Sampson J. Pre-cryoablation Embolization of Renal Tumors: Decreasing Probes and Saving Loads. Cureus. 2018 Dec;10(12):e3676.

18 Ng KK, Lam CM, Poon RT, Shek TW, To JY, Wo YH, et al. Comparison of systemic responses of radiofrequency ablation, cryotherapy, and surgical resection in a porcine liver model. Ann Surg Oncol. 2004 Jul;11(7):650-7.

19 Bastianpillai C, Petrides N, Shah T, Guillaumier S, Ahmed HU, Arya M. Harnessing the immunomodulatory effect of thermal and non-thermal ablative therapies for cancer treatment. Tumour Biol. 2015 Dec;36(12): 9137-46.

20 Edinger AL, Thompson CB. Death by design: apoptosis, necrosis and autophagy. Curr Opin Cell Biol. 2004 Dec; 16(6):663-9.

21 Joosten JJ, Muijen GN, Wobbes T, Ruers TJ. In vivo destruction of tumor tissue by cryoablation can induce inhibition of secondary tumor growth: an experimental study. Cryobiology. 2001 Feb;42(1):49-58.

22 Kato T, Iwasaki T, Uemura M, Nagahara A, Higashihara H, Osuga K, et al. Characterization of the cryoablationinduced immune response in kidney cancer patients. OncoImmunology. 2017 May;6(7):e1326441.

23 Camara O, Rengsberger M, Egbe A, Koch A, Gajda M, Hammer U, et al. The relevance of circulating epithelial tumor cells (CETC) for therapy monitoring during neoadjuvant (primary systemic) chemotherapy in breast cancer. Ann Oncol. 2007 Sep;18(9):1484-92.

24 Katharina P. Tumor cell seeding during surgery-possible contribution to metastasis formations. Cancers (Basel). 2011 Jun;3(2):2540-53.

25 Coffey JC, Wang JH, Smith MJ, Bouchier-Hayes D, Cotter TG, Redmond HP. Excisional surgery for cancer cure: therapy at a cost. Lancet Oncol. 2003 Dec;4(12):760-8.

26 Fisher B, Fisher ER. Transmigration of lymph nodes by tumor cells. Science. 1966 Jun;152 (3727):1397-8.

27 Nguyen DX, Bos PD, Massagué J. Metastasis: from dissemination to organ-specific colonization. Nat Rev Cancer. 2009 Apr;9(4):274-84.

28 Zhao T, Xia WH, Zheng MQ, Lu CQ, Han X, Sun YJ. Surgical excision promotes tumor growth and metastasis by promoting expression of MMP-9 and VEGF in a breast cancer model. Exp Oncol. 2008 Mar;30(1):60-4.

29 Da Costa ML, Redmond HP, Finnegan N, Flynn M, Bouchier-Hayes D. Laparotomy and laparoscopy differentially accelerate experimental flank tumour growth. Br J Surg. 1998 Oct;85(10):1439-42. 